\title{
O desenvolvimento de um framework descritivo de ductus caligráfico
}

The design of a descriptive framework for the calligraphic ductus

NOVAIS, Carlos Eduardo B.; Mestre e Doutorando; Universidade Federal do Ceará eduardonovais@virtual.ufc.br

MOREIRA, Eduardo O.; Designer e Mestrando; Universidade Federal de Pernambuco

eduardo.oliveira.m@gmail.com

Coutinho, Solange; PhD; Universidade Federal de Pernambuco

solange.coutinho@ufpe.br

\section{Resumo}

O presente trabalho lança um olhar exploratório sobre o tema e propõe um estudo específico a respeito do ductus caligráfico, abordando-o como uma sequência pictórica de procedimento (SPP) e propondo um framework de análise específico para esse tipo de SPP. A metodologia para desenvolver o framework de análise se deu em três etapas: (1) uma análise da viabilidade de sua aplicação, (2) análise dos ductus caligráficos e (3) testes de eficácia do framework. O estudo gerou duas versões de framework, sendo o primeiro mais descritivo e o segundo mais prático para a coleta de dados, funcionando como uma checklist. Os testes demonstraram que o framework se apresenta como uma ferramenta eficaz de análise, auxiliando a descrição e análise de diversos modelos. Ainda assim, mostrou-se necessário novas categorias para uma análise de um modelo caligráfico.

Palavras Chave: caligrafia; ductus; sequência pictórica de procedimentos; design de informação.

\section{Abstract}

The present paper examines the subject and proposes a specific study about the calligraphic ductus, approaching it as a pictorial sequence of procedure (SPP) and proposing a specific analysis framework for this type of SPP. The methodology to develop the analysis framework was made in three stages: (1) an analysis of the feasibility of its application, (2) analysis of the calligraphic ductus and (3) tests on the effectiveness of the framework. The study generated two versions of the framework, the first being more descriptive and the second more practical for data collection, functioning as a checklist. The tests demonstrated that the framework presents itself as an effective tool of analysis, aiding the description and analysis of several calligraphic models. Nevertheless, we realize that new categories are needed for a better analysis of a calligraphic model.

Keywords: calligraphy; ductus; pictorial sequence of procedures; information design. 


\section{Introdução}

A proposta deste trabalho surgiu da constatação de que, dos poucos estudos a respeito do ensino de caligrafia conduzidos no Brasil, nenhum deles tratou de estudar especificamente o ductus caligráfico, seja como estrutura para o desenho dos caracteres ou analisando-o como uma sequência pictórica de procedimentos. Acreditamos que pesquisas dessa natureza se tornam importantes para gerar novas discussões a respeito da caligrafia e o seu ensino, bem como contribuir para que o tema seja cada vez mais investigado em âmbito acadêmico. Sendo assim, para avaliar os tipos de escrita, tomamos como referência a classificação de Loaiza, Valencia e Arias (2010) que divide a caligrafia em três grandes grupos: (I) escrita, (II) histórica e (III) expressiva. Desse modo, como objetivo principal, este estudo buscou compreender como se configurava uma SPP, de que maneira um ductus caligráfico poderia ser considerado como tal e como poderíamos analisa-lo. Nessa perspectiva, buscou-se compreender cada uma das variantes propostas no framework para descrição de representações gráficas apresentado por Spinillo (2000), propor um novo e mais específico na análise dos ductus dos modelos caligráficos escolhidos para verificar a eficiência do framework proposto.

\section{Referencial Teórico}

É importante definirmos alguns dos termos que serão utilizados no decorrer deste artigo. Assim, iniciamos uma discussão sobre o que é ductus, sua epistemologia e como ele é atualmente entendido nos estudos sobre escrita e caligrafia. Em seguida, discutimos o que é uma Sequência Pictórica de Procedimentos de acordo com Spinillo (2000) e apresentamos o framework de análise de SPPs criado pela autora. Por fim, relacionamos pontos necessários numa SPP e indicamos como eles estão presentes no ductus caligráfico configurando-o, então, como tal.

\subsection{O Ductus}

Ductus, de acordo com o dicionário Michaelis da Língua Portuguesa (2018), é uma palavra de origem latina que significa duto ${ }^{1}$ ou canal ${ }^{2}$. No contexto da escrita, a palavra adota um significado análogo, um meio de condução ao resultado final da caligrafia. De acordo com Mediavilla (2005), o ductus se refere à construção do caractere caligráfico, normalmente apresentado por meio de uma sequência de procedimentos que orienta o praticante do início ao fim do desenho de uma letra.

É o ductus, então, que demonstra, por meio de uma série de procedimentos, a sequência e sentidos dos traços necessários para a construção do signo caligráfico. Através do ductus é possível precisar a ordem em que os traços são gerados, bem como o sentido, angulação do instrumento de escrita, altura e inclinação do eixo dos caracteres (MEDIAVILLA, 2005). Para Lima (2009), o ductus representa a essência de um modelo caligráfico. Do ponto de vista morfológico, ele se constitui como a armação por onde o caractere toma forma, por meio de características referentes à sua execução, à ferramenta e ao suporte. Nesse sentido, o ductus caligráfico seria o elemento principal de um modelo caligráfico.

Apesar de ser facilmente observável em livros e apostilas de cursos de ensino de caligrafia

\footnotetext{
${ }^{1}$ Tubo ou tubulação que se destina a conduzir substâncias.

${ }^{2}$ Canal pode ter o significado de "meio, caminho ou via".
} 
escrita, não foram observados estudos que abordam o ductus caligráfico como o modelo de construção de um caractere. Em geral, a escrita é abordada de um ponto de vista da lectoescrita (FERREIRO; TEBEROSKY, 1999), histórica (FETTER, 2012) ou pedagógica (SMOLKA, 2012).

Neste campo, observou-se que a própria nomenclatura não é precisa. Enquanto alguns autores se utilizam do termo ductus (FETTER, 2012; HEITLINGER, 2011; LIMA, 2009; LOAIZA; VALENCIA; ARIAS, 2010; MEDIAVILLA, 2005), é também possível encontrar o mesmo modelo definido como sequência de traços (stroke sequence) (HARRIS, 2003, 2013; NEWHALL, 1989).

Compreendendo o ductus como tal, pode-se avaliar como ele se comporta para cada tipo de caligrafia. Como mencionando anteriormente, Loaiza, Valencia e Arias (2010) utilizam a classificação da caligrafia em três modos distintos: como (I) escrita, (II) histórica e (III) expressiva.

No primeiro modo compreende-se a caligrafia como escrita. O foco é a legibilidade e uma efetiva comunicação. Este modo é voltado à aprendizagem escolar da escrita, ensinada para crianças em processo de alfabetização. Para tal o ductus nesse tipo de caligrafia deve levar em consideração a idade do aprendiz e suas limitações quanto a aquisição de informações visuais e seu nível de alfabetização.

Figura 1 - Exemplo de ductus de caligrafia escolar da letra " $q$ ".
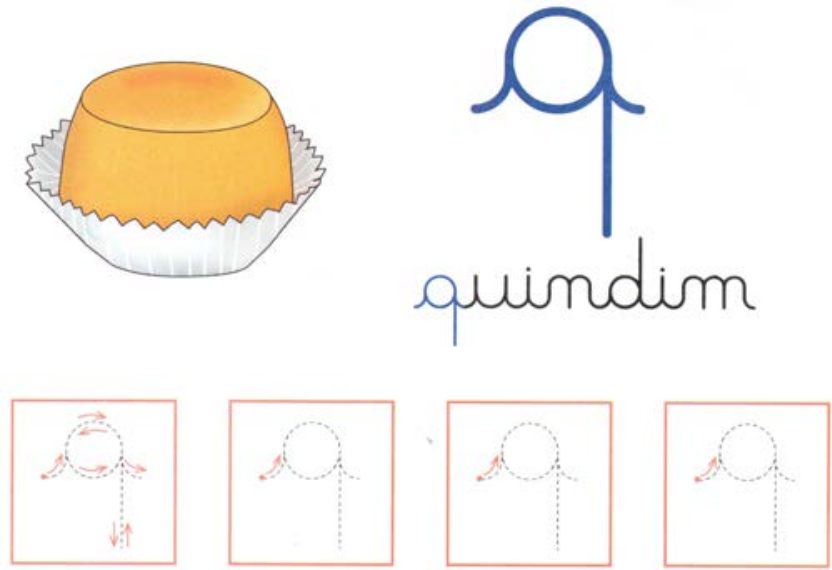

Fonte: (GABRYELLE; CARLA, 2013).

A segunda categoria compreende a caligrafia de caráter paleográfico ou histórico, onde são evidenciados a estrutura e os aspectos grafêmicos das letras. Neste modo de configuração da caligrafia, o principal exemplo seria o ductus de configuração de modelos históricos tais como, o modelo fundamental, as unciais, góticas fraktur, etc. (figura 2).

O último modo proposto pelos autores diz respeito à atividade expressiva ou experimental da caligrafia. Compreende-se neste trabalho que este tipo de atividade, supostamente autoral, não comporta a existência de modelos de desenvolvimento pré-estabelecidos, mas sim referências a modelos históricos. No exemplo da figura 3, observa-se uma livre apropriação de modelos e técnicas para o desenvolvimento de uma peça expressiva e pessoal. 
Figura 2 - Ductus de um modelo de caligrafia histórico das letras "a", "b", "c" e "d".

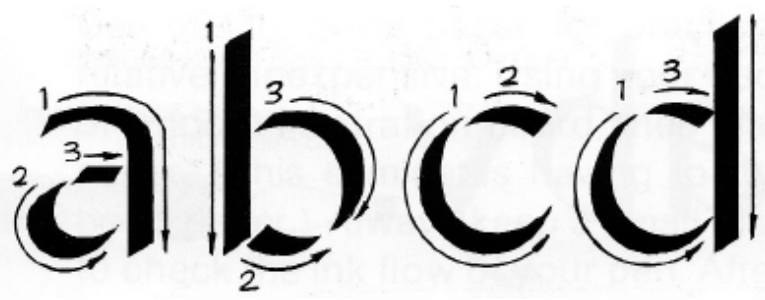

Fonte: (NEWHALL, 1989).

Figura 3 - Exemplo de caligrafia expressiva desenvolvida pelo calígrafo brasileiro Claudio Gil.

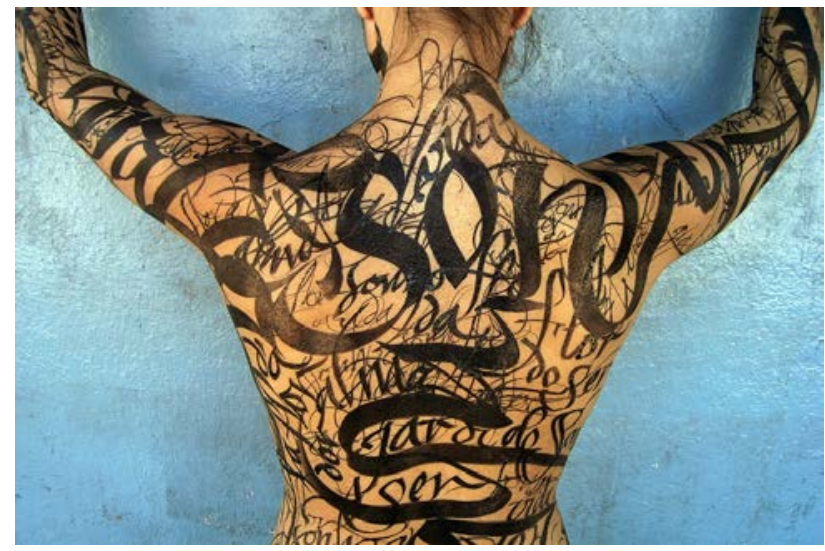

Fonte: (GIL, 2008).

Historicamente os dois primeiros modos de compreensão da caligrafia tinham sentidos aproximados até o início do século XX. Esteves (2000) descreve como os termos eram compreendidos de forma semelhante até o final da década de 1910:

Os termos caligrafia e escrita eram utilizados como sinônimos, posto que no entendimento dos educadores definiam o mesmo objeto: instrumento que habilita a manifestação rápida e clara do pensamento. A caligrafia/escrita era, ainda, compreendida como um complemento para o ensino da leitura. (ESTEVES, 2000, p. 3)

Essa diferenciação entre os dois termos e, consequentemente, a compreensão do conteúdo ensinado nas escolas para as crianças, aparece de forma mais acentuada durante as décadas de 1920 e 1930 quando vem à tona uma forte campanha entre prol do uso da caligrafia vertical. Segundo Fetter (2012), é neste momento que a aplicação de métodos de ensino e modelos caligráficos históricos são retirados do currículo escolar, fruto de uma visão que entendia a caligrafia como um meio de comunicação e não mais como um fim. Desta forma, pode-se observar que os modelos caligráficos, tanto da escrita escolar como o os históricos, têm uma mesma origem, diferenciando-se, pelo menos no Brasil, a partir das décadas de 1920 e 1930.

\subsection{Sequências Pictóricas de Procedimentos (SPPs)}

Sequências Pictóricas de Procedimentos podem ser definidas como elementos ou eventos 
representados pictoricamente para descrever ou explicar processos, ou seja, representações de instruções sequenciais feitas por meio de imagens (SPINILLO, 2000, 2002).

A análise desse tipo de representação de um procedimento tem despertado interesse em função de sua crescente importância. Segundo Richards (2000), quando a documentações de procedimentos são projetadas de forma eficiente, os custos de manutenção e treinamento de produtos diminuem consideravelmente.

Para a plena compreensão deste recurso, deve-se compreender o uso dos termos procedimento e picture (do inglês: imagem, quadro). Neste trabalho, utiliza-se a definição de Spinillo, que compreende procedimento como "um conjunto de etapas a serem realizadas" (SPINILLO, 2000) e picture como "a representação figurativa de algo que traz propriedades icônicas do que é retratado" (op. cit). A definição corrobora com a utilizada por Twyman que define picture como "qualquer imagem feita a mão ou por uma máquina que se relaciona, ainda que distantemente, com a aparência de coisas reais ou imaginárias" (1985, p. 249).

Além demonstrar tais definições, é preciso compreender o espaço do elemento pictórico na linguagem gráfica. Para tal, é apresentado o modelo de linguagem proposto por Twyman (1982), o qual tem suas bases nos princípios e compreensões linguísticas e gráfica (figura 4).

Segundo sua abordagem, a linguagem pode ser dividida em dois grandes grupos: a Auditiva e a Visual. Para o grupo composto da linguagem Auditiva, o autor se diz satisfeito em dividi-lo somente entre verbal e não-verbal, deixando aos linguistas a responsabilidade de estudos sobre esta ramificação de seu esquema.

Figura 4 - Modelo de Twyman que engloba uma abordagem linguística e gráfica em relação à linguagem.

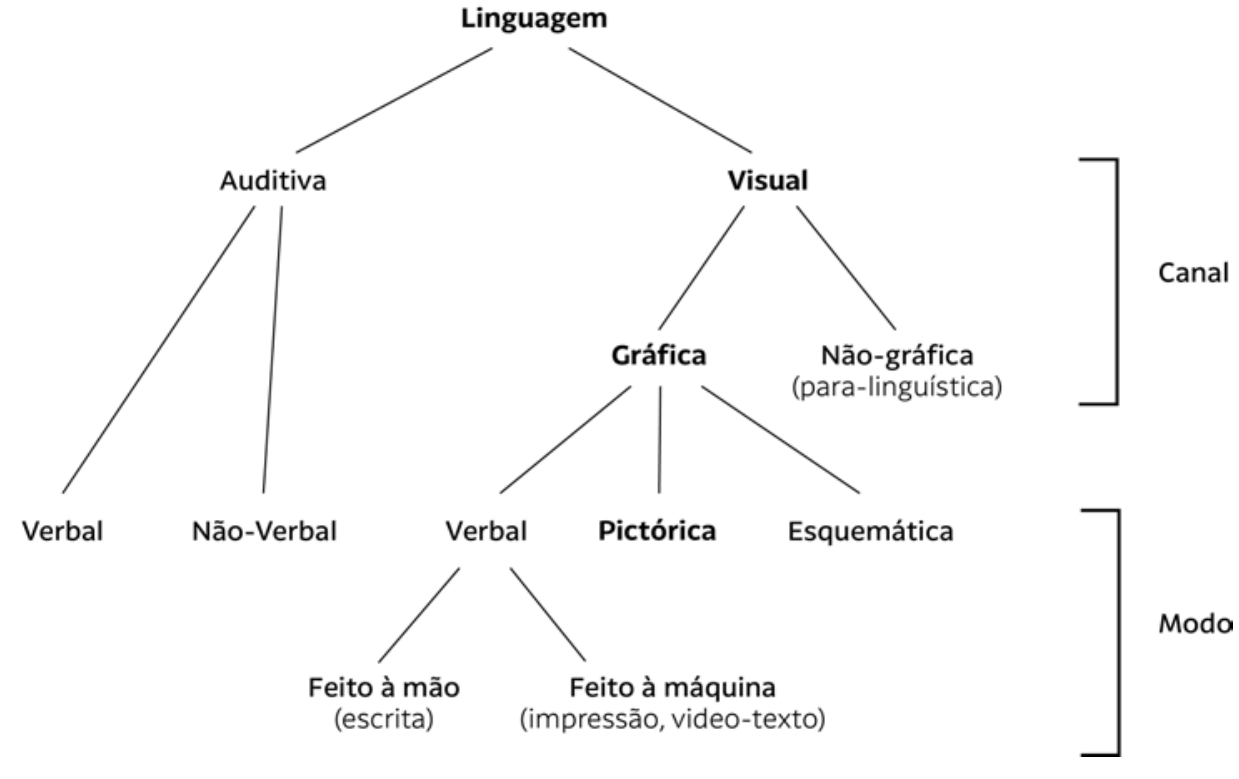

Fonte: (TWYMAN, 1982). Tradução nossa.

A linguagem visual apresenta em seu modelo a divisão entre gráfica e não gráfica (ou paralinguística). Como tal, deve-se compreender áreas da linguagem visual como gestos e expressões faciais, entendendo as demais dimensões da linguagem visual como linguagem visual gráfica (LVG). Esta, pode ser dividida em três modos: a Verbal, Pictórica e Esquemática, cada uma delas 
podendo ser desenvolvidas manualmente ou através de algum tipo de máquina/mecanismo.

Ao se referir a um elemento pictórico neste estudo, compreende que tal como um elemento visual gráfico - desenvolvido a mão ou por meio de uma máquina - cuja configuração não seja nem verbal e nem esquemática. Ainda assim, Twyman (1985) lembra que a definição de um elemento como pictórico ou esquemático não é uma tarefa trivial, devendo-se sempre observar circunstâncias particulares de seu uso e a compreensão do leitor.

Dado que as SPPs comunicam a mensagem de um procedimento que deve ser executado, Spinillo (2000) indica que a principal modo de simbolização das SPPs é como linguagem visual gráfica pictórica. Enquanto que os textos, números e outras letras presentes podem ser identificados como um modo linguagem visual verbal.

\subsection{A Definição do Ductus como uma SPP}

Sendo o ductus um esquema pictórico que descreve procedimentos para a execução de um caractere, podemos classificá-lo como uma sequência pictórica de procedimentos. Ainda que o seu objeto de representação seja uma letra, tipicamente um elemento de linguagem gráfica verbal, o ductus pode ser classificado como imagem de um procedimento para a construção de um caractere.

É importante ressaltar o papel deste elemento gráfico frente aos dois tipos de caligrafia abordados neste trabalho (histórico e escolar). Para um iniciante que busca aprender a escrever, o caractere representado na SPP possui em um primeiro momento uma característica pictórica mais acentuada. Esta característica, à medida que a criação do caractere se converte em um processo adquirido, faz com que o elemento ganhe cada vez mais importância verbal. Entende-se o processo para o aprendiz de caligrafia histórica como inverso. Considerando que o aprendiz já é alfabetizado, o primeiro contato com o ductus é de forte referência verbal, importante para encontrar o elemento. Após esta busca, a utilização será como um elemento pictórico, buscandose a reprodução de detalhes de execução que vão além da legibilidade e comunicação verbal.

Uma das primeiras considerações que se deve fazer sobre uma SPP é sobre a quantidade de quadros utilizados para sua exibição. Caso a SPP represente toda a sequência em um único quadro é classificada como sinóptica. Caso sejam utilizados mais de um quadro para representar todo o movimento, considera-se a SPP como uma sequência discreta (SPINILLO, 2000).

Em relação à quantidade de passos demonstrados em um quadro, quando vários passos de são representados em uma única imagem, o quadro é considerado implícito. Quadros com único passo são explícitos (SPINILLO, 2000).

A primeira característica se refere a configuração da SPP como um todo e a segunda ao quadro analisado. Na figura 5 a, por demonstrar todo o procedimento em uma única imagem ou quadro, considera-se este SPP como sinóptica. O quadro, é classificado como implícito por demonstrar mais de um passo em um único quadro. Enquanto isso, na figura $5 b$, observa-se a existência de dois quadros cuja sugestão de separação é apenas o espaço entre eles. Por demonstrar o procedimento em mais de um quadro, pode-se considerar a SPP como discreto. Enquanto isso, o segundo quadro demonstra somente o último passo necessário para a finalização da tarefa, considerando-se como um explícito. 
Figura 5 - (a) Sinóptica com quadro implícito; (b). Discreta com quadro explícito.
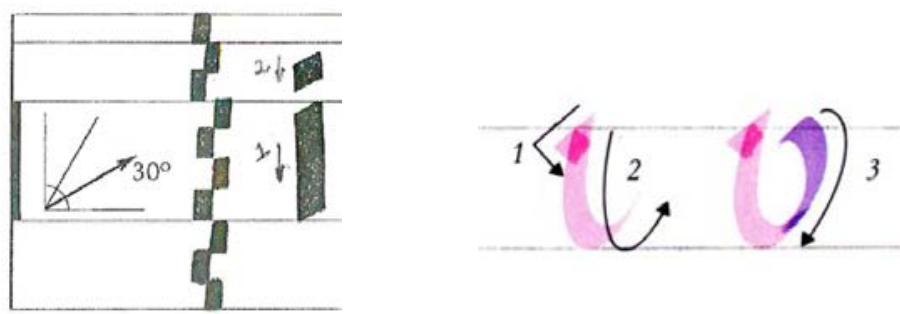

Fonte: Branco (2012) e Harris (2013).

\section{Metodologia}

Após a revisão e fundamentação teórica da área da Caligrafia e do Design da Informação, a pesquisa buscou desenvolver de um framework de análise de ductus caligráfico, para os casos da caligrafia escolar ou histórica.

Como ponto de partida, tomou-se como modelo o framework de análise de sequências pictóricas de procedimentos (SPP) proposto por Spinillo (2000). Sua proposta é direcionada às características imagéticas de SPPs, levando em consideração a integração do texto com a sequência pictórica. O framework de Spinillo (2000) apresenta-se como uma tabela cuja primeira coluna lista as diversas variáveis de análise da SPP. A saber: (1) Apresentação do Texto, a maneira pela qual os textos são exibidos em relação às imagens; (2) Arranjo dos quadros, a forma como as imagens são alinhadas; (3) Guias de leitura, os elementos utilizados para tornar a orientação da sequência explícita; (4) Sugestões de separação visual, as dicas gráficas usadas para separar os quadros da sequência; (5) Dispositivos Simbólicos, convenções estabelecidas ou usadas dentro de um contexto particular; (6) Dispositivos enfáticos, os meios utilizados para enfatizar um aspecto particular, seja chamando a atenção do leitor ou mostrando detalhes da imagem; (7) Estilos de Imagem, as qualidades gráficas ou ingredientes que pertencem a diferentes imagens representativas; e (8) Tipo de Representação, a representação em sua forma completa ou incompleta. A segunda coluna é reservada para entrada de informações sobre as diferentes formas que as variáveis podem ser apresentadas na sequência. Por fim, a terceira coluna é reservada para variações que cada forma que a variável pode se apresentar. O quadro abaixo demonstra o framework descritivo para representações gráficas de Spinillo (2000).

Quadro 1 - Framework descritivo para representações gráficas.

\begin{tabular}{l|l|l}
\hline Variables & Description & Variation \\
\hline 1. Text presentation & & \\
2. Arrangement & & \\
3. Reading guides & & \\
4. Visual separation cues & & \\
5. Symbolic devices & & \\
6. Emphatic devices & & \\
7. Picture style & & \\
8. Depiction & & \\
\hline
\end{tabular}

Fonte: (SPINILLO, 2002). 
Após a apresentação de seu modelo, a autora apresenta as diversas formas em que cada variável pode ser descrita. As possíveis descrições para cada variável de análise são:

Quadro 2 - Variáveis para análise de SPP.

\section{Apresentação do texto}

$\begin{array}{lll}\text { a) Legenda; } & \text { b) Texto corrido; e } & \text { c) Rótulo. } \\ \text { 02. Arranjo dos quadros } & & \\ \begin{array}{lll}\text { a) Horizontal; } & \text { b) Vertical; } & \text { c) Oblíquo; } \\ \text { d) Ramificado; e } & \text { e) Circular. } & \end{array}\end{array}$

\section{Guias de leitura}
a) Números;
b)Letras;
c) Setas; e
d) Outros.
d) Outros;

04. Sugestões de separação visual
a) Espaços;
b) Linhas; e
c) Limites.

05. Dispositivos Simbólicos
a) Pictogramas
b) Sugestão de
c) Outros

movimentos; e

\section{Dispositivos Enfáticos}
a) Formas
b) Contraste Figura-Fundo
c) Outros.

\section{Estilos de imagem}
a) Fotográfico
b) Desenho;
c) Esquema; e
d) Estilo de sombras.

\section{Tipo de Representação}
a) Parcial; e
b) Total.

Fonte: Desenvolvido pelos autores com base em Spinillo (2000). Tradução nossa.

Notações sobre o arranjo de quadros (02) ou sobre sugestões de separação (04) só se fazem necessárias quando a SPP é discreta.

O desenvolvimento do modelo de descrição de ductus caligráficos, escolares ou históricos, deu-se após três fases: (i) análise da viabilidade de aplicação das variáveis e suas descrições; (ii) análise do ductus caligráficos de livros de caligrafia histórica e escolar para identificação de dispositivos simbólicos específicos da área e (iii) testes de aplicabilidade do framework proposto.

A importância da determinação da SPP como sinóptica ou discreta levou os autores a inserir uma nova variável chamada configuração da SPP. Cada uma das nove variáveis (as oito sugeridas pela autora e mais a variável de configuração da SPP, sugerida pelos autores) foram então dispostas cada uma em uma tabela listando nas linhas cada um dos caracteres e nas colunas cada possível descrição assumida pela variável. O modelo, inicialmente complexo pela quantidade de tabelas e valores disponibilizados, mas pretensiosamente ágil em seu preenchimento é apresentado na figura 6.

A razão dessa alteração em relação ao framework de Spinillo (2000) foi simplificar seu preenchimento. Enquanto o modelo original foi pensado para analisar uma única SPP, o modelo proposto para análise de SPPs de modelos caligráficos trabalho pelo menos 26 sequências (um para cada caractere do alfabeto). 
Figura 6 - Framework de análise de ductus caligráficos.
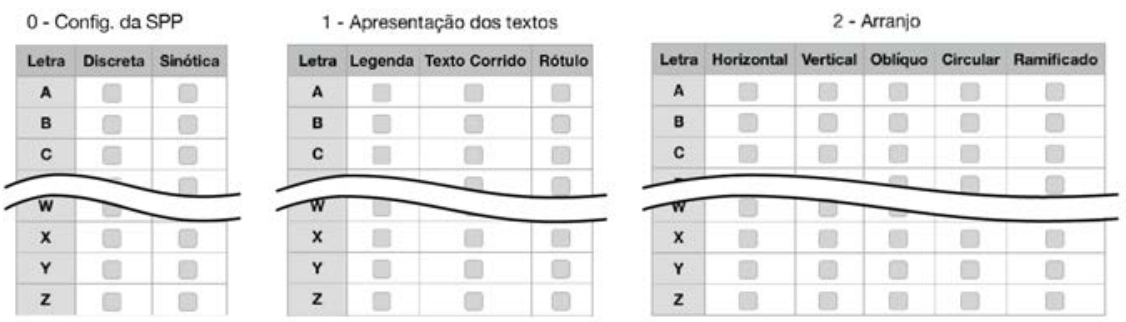

3 - Guias de leitura

5 - Dispositivos Simbólicos

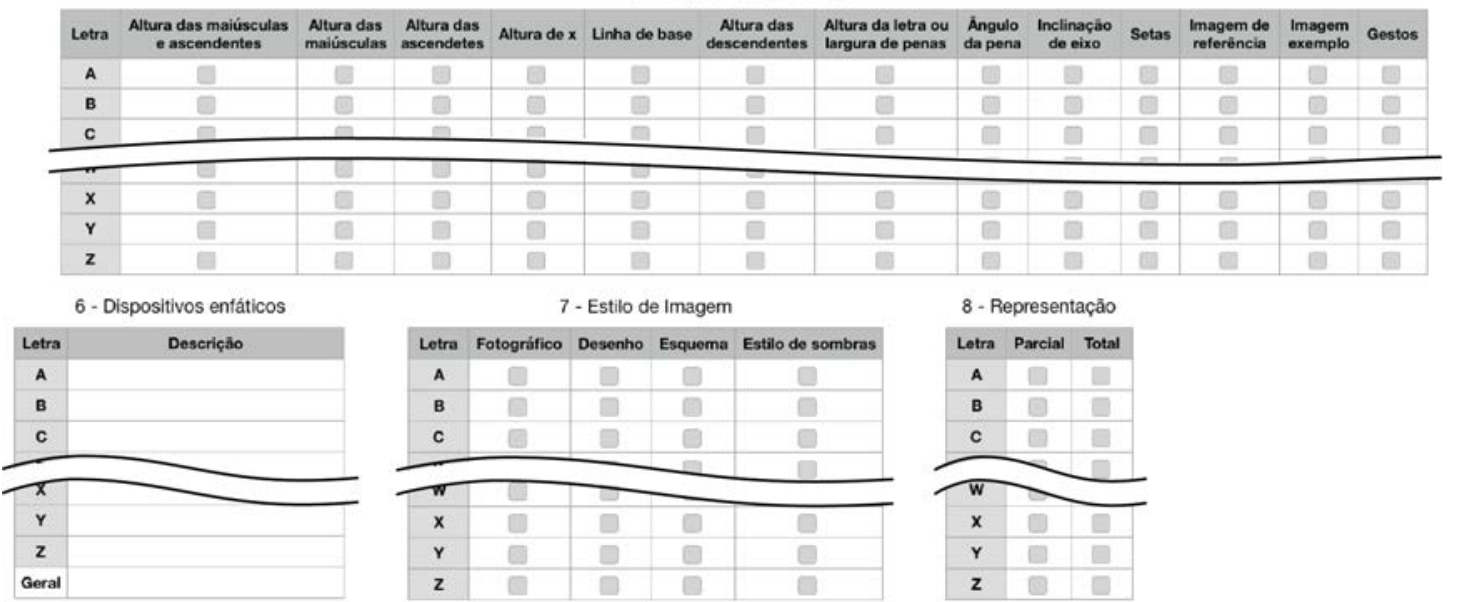

Fonte: Desenvolvido pelos autores.

Sendo aplicável para diversos tipos de procedimentos, é compreensível que o quadro de descrição de Spinillo (2000) dê liberdade ao avaliador para compor a análise de dispositivos simbólicos. Em caligrafia são vários os dispositivos simbólicos historicamente utilizados. Para listar alguns dos mais recorrentes destes dispositivos, foram analisados ductus em livros de caligrafia escolar (GABRYELLE; CARLA, 2013) e de caligrafia histórica (HARRIS, 2003, 2013).

Os dispositivos simbólicos utilizados encontrados foram: Altura das maiúsculas (limite de altura das letras maiúsculas); altura das ascendentes (limite de altura dos traços que se projetam em letras como I, b e d); altura de " $x$ " (limite para as letras minúsculas); linha de base (linha fundamental de apoio das letras); altura das descendentes (limite das hastes que se projetam abaixo da linha de base - pode ser observado em letras como g, p, q e y); altura da letra ou largura de penas (referência de altura da letra em relação à largura da pena utilizada); ângulo da pena (nível de rotação da pena chata para execução dos traços); inclinação de eixo (referência visual para inclinação de cada letra); setas (indicadores de direção do traço); imagem de referência (recurso visual para demonstrar o contexto de aplicação do caractere); imagem exemplo (imagem de como seria o modelo da letra perfeitamente executado); e gestos (imagens de como a mão ou o corpo do calígrafo precisa estar postado para melhor execução do traço).

\section{Examinando a Eficiência do Framework Proposto}

Para verificar a eficiência do modelo proposto, foram avaliados um modelo de caligrafia cursiva escolar (Gabryelle e Carla, 2013), um modelo de maiúsculas imperiais (Harris, 2013), um modelo de maiúsculas fundamentais (Harris, 2003) e dois modelos de minúsculas fundamentais 
(Harris, 2003 e 2013). A escolha dos modelos possibilita por um lado uma amplitude de modelos analisados, testando o framework sob diversas circunstâncias. Por outro lado, suscita avaliações comparativas entre modelos, tais como as minúsculas fundamentais de Harris (2003 e 2013); entre o desenho das maiúsculas e minúsculas de um mesmo modelo (Harris, 2003); e, por fim, entre um modelo de caligrafia escolar e um modelo de caligrafia histórica (Gabryelle e Carla, 2013; Harris, 2013).

Durante o preenchimento dos dados para cada modelo, foram realizados ajustes para adequação para cada campo. Nos dispositivos simbólicos além das convenções tradicionais da caligrafia, como as linhas de referências, por exemplo; foram inseridos campos referentes a imagens de exemplo, ou seja, como o caractere deveria parecer após sua execução; como também o de imagem de referência, a inserção de imagens que apresentem referências ao uso do caractere. Na caligrafia escolar é comum indicar palavras que começam com determinado letra ou o uso da letra dentro do contexto de uma palavra ou pequeno texto, por exemplo.

A proposta para o preenchimento do campo dos dispositivos enfáticos foi deixa-lo aberto, sem sugestões de preenchimento. Foi inserido nesse campo de análise um campo geral. A ideia desse campo é gerar um espaço para considerações sobre dispositivos enfáticos utilizados da mesma forma para todos os caracteres, evitando, assim, repetições desnecessárias.

O preenchimento da tabela para cada modelo revelou-se por vezes repetitivo. Entretanto, à medida que os dados eram registrados, detalhes evidenciavam características e tomadas de decisões dos autores que aos poucos demonstravam características de cada modelo. A figura 7a mostra os dados coletados após a análise do ductus de um modelo caligráfico escolar, enquanto a figura 7b demonstra o mesmo para o ductus de um modelo histórico. Por conta do público, crianças de 5 a 6 anos, as minúsculas escolares de Gabryelle e Carla (2013) demonstravam imagens de referência, além das imagens de exemplo para todas as letras.

Figura 7 - Análise do ductus do caractere "c" de um modelo escolar (a) e de um histórico (b).
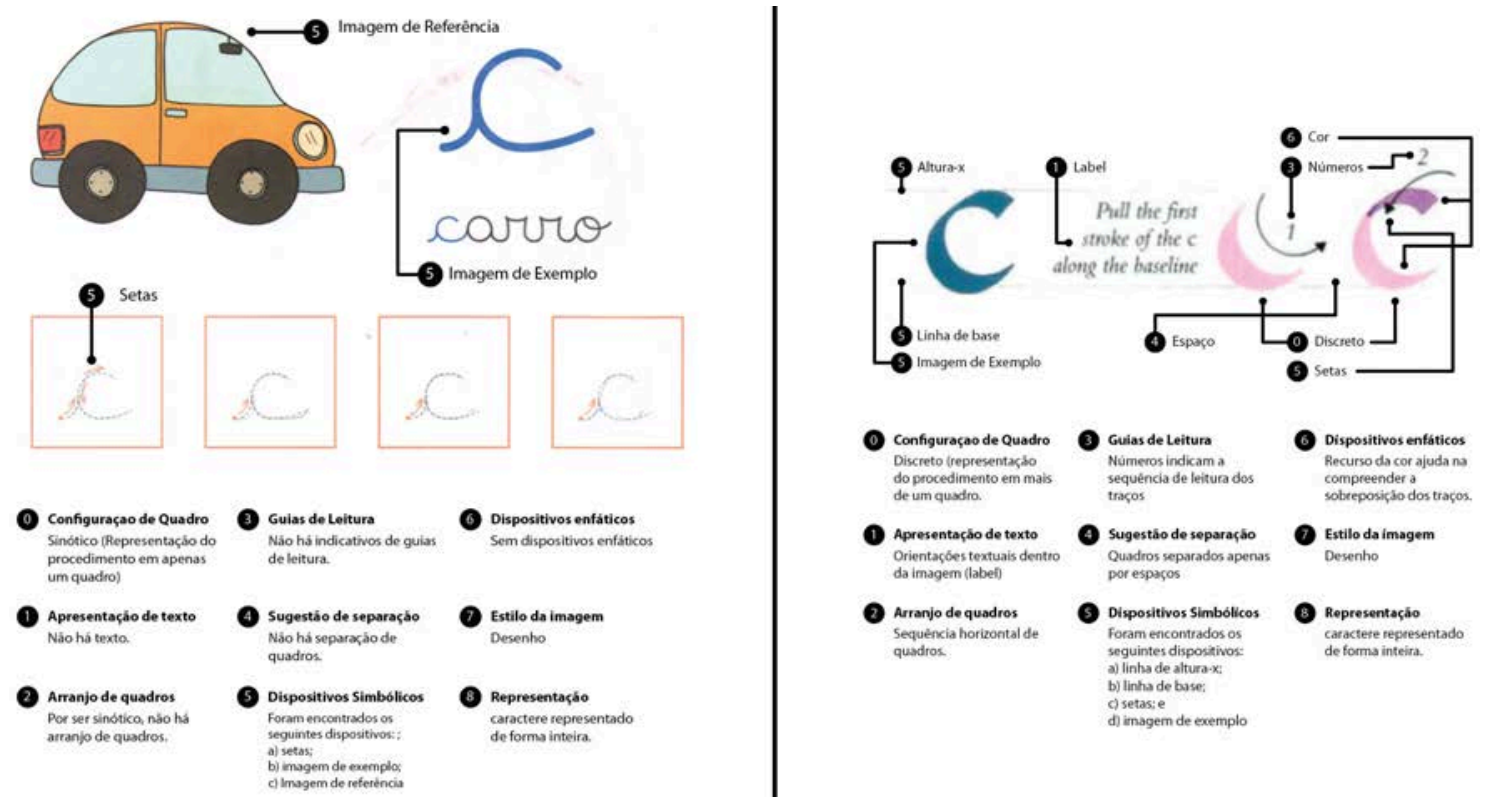

Fonte: Desenvolvido pelos autores com base nos ductus de Gabryelle e Carla (2013) e Harris (2013). 
Analisando os dados, constatou-se que as decisões sobre quais informações exibir e como exibi-las, em geral, são mantidas para todo o conjunto de SPPs para um modelo caligráfico. Entretanto, a análise individual de caracteres se mostra essencial para revelar particularidades de cada sequência de procedimentos.

No que diz respeito à configuração de quadros, as SPPs são sinópticas em sua maioria. Os fatores que levam a esta decisão é que parecem diferentes. Em Harris (2003), somente quatro letras por modelo são demonstradas de forma discreta. Por outro lado, em Harris (2013) quase todos os ductus possuem dois ou mais quadros. Em Gabryelle e Carla (2013), como o público é formado por crianças em fase de aprender a desenhar as letras, é possível que a decisão se dê em função do nível cognitivo.

Ao contrário do que indica o seu nome, o livro A Calligrapher's Bible de David Harris (2003) é um livro sucinto, onde os procedimentos são demonstrados em uma única página e apenas alguns detalhes são demonstrados em quadros separados, tais como a SPP das letras "o", "n", "g" e "s" nas minúsculas fundamentais e as letras "I", "S", "T" e "V" nas maiúsculas fundamentais.

Figura 8 - Exemplos de SPPs sinópticas e discretas.
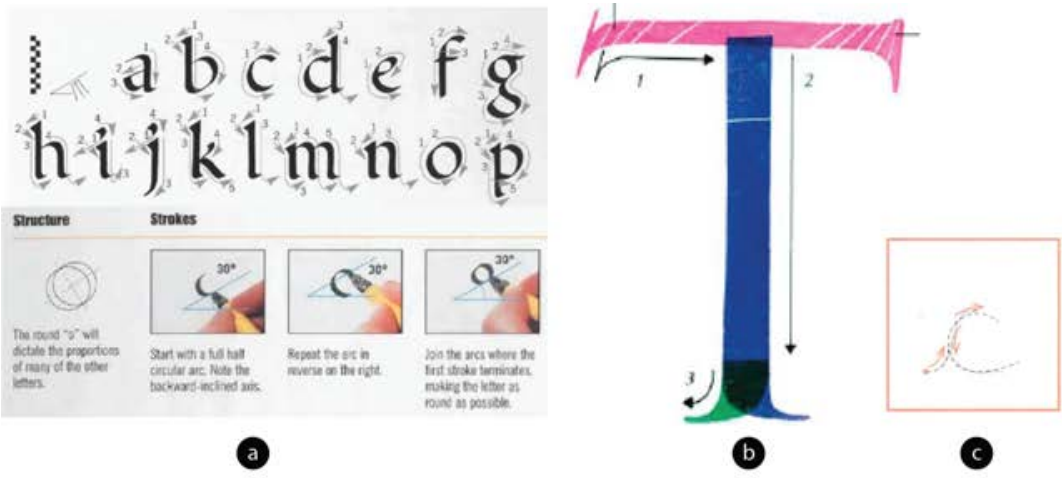

Fonte: (a) Harris (2003), (b) Harris (2013) e Gabryelle e Carla (2013)

A exceção à regra acontece em A Arte da Caligrafia (2013), também de David Harris. Neste livro, as SPPs foram concebidas, em geral, como discretas. Nas minúsculas fundamentais, apenas as letras "i" e "j" possuem SPPs sinópticas (figura 9). Ainda assim, ao demonstrar o modelo caligráfico das capitulares imperiais, o autor opta novamente por quadros únicos (figura 10).

Figura 9 - Harris opta por SPPs discretas. Ductus de "i" e "j" são exceções.

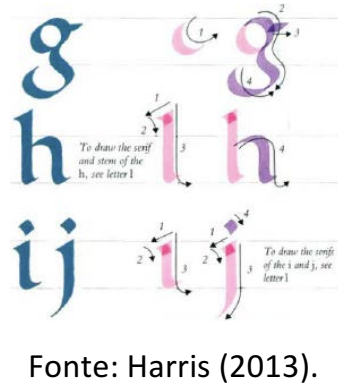

A demanda por informações não-procedimentais, refletida na inserção de textos dentro de 
SPPs aumenta à medida que cresce o grau de complexidade do procedimento. O modelo caligráfico escolar, novamente, em função de seu público, configura-se de modo simples o suficiente para não precisar de qualquer informação textual. No outro extremo estão as capitulares imperiais, cuja a execução demanda tantas informações que são inseridas como rótulos e também legendas.

Enquanto o desenvolvimento de um "c" manuscrito escolar (figura 7a) necessita de poucos procedimentos e de fácil execução, o ductus da letra " $A$ " (figura 10) maiúscula Imperial faz uso de legendas e rótulos para explicar informações sobre sequência de traços, angulações da pena, etc.

Figura 10 - Ductus para desenvolvimento de um " $\mathrm{A}$ " no estilo das maiúsculas Imperiais.

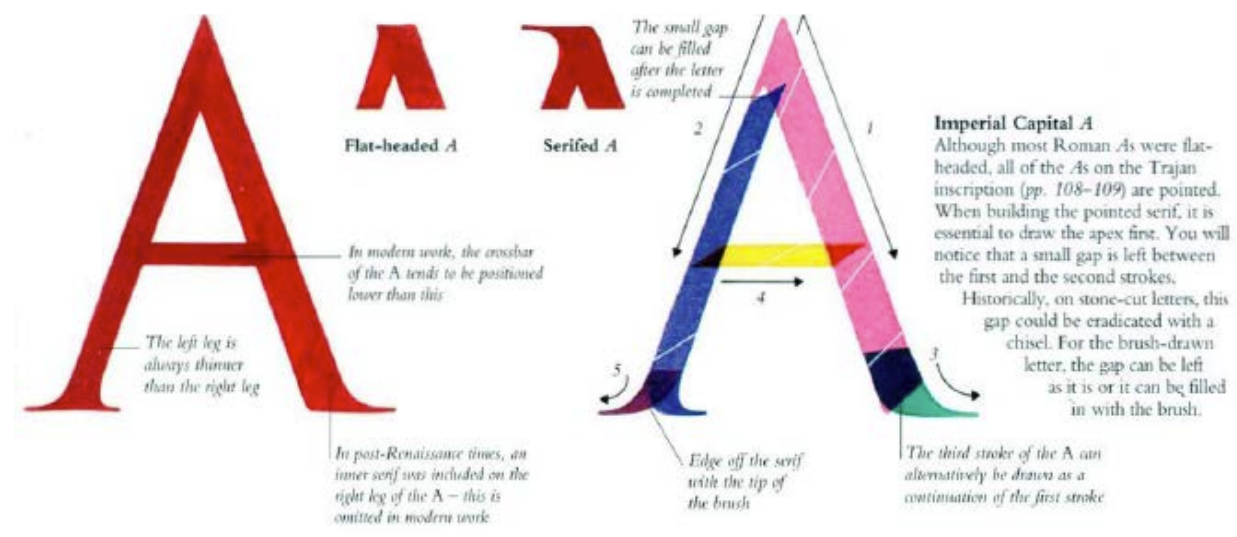

Fonte: Harris (2013).

Os arranjos dos quadros das SPPs projetadas de forma discreta são em $100 \%$ dos casos horizontais. Ainda nesse caso, o recurso do espaço vazios entre as etapas é o mais comum. Observou-se o uso de quadro separados por linha de borda somente nas SPPs detalhadas das maiúsculas e minúsculas fundamentais de Harris (2003) (Ver exemplo do ductus do "o" na figura 8a).

Com relação aos dispositivos simbólicos, surpreende que alguns dos mecanismos mais comumente associados a uma pauta caligráfica - seja ela escolar ou histórica - esteja ausente em boa parte dos ductus analisados. Linhas de ascendentes, maiúsculas e de descendentes não foram observadas em nenhum dos modelos analisados. A omissão destas linhas na caligrafia escolar é um fator comum. Entretanto, tais referências são consideradas essenciais para uma correta execução da caligrafia de diversos modelos históricos e, ainda assim, estão ausentes. Até mesmo a linha de base, apontada como "a mais importante de todas as linhas auxiliares" (HEITLINGER, 2011) é omitida no grupo da caligrafia cursiva escolar e nas maiúsculas imperiais. Em Harris (2013), verificou-se a presença desta linha e da linha de altura-x em todos as SPPs analisadas. Entretanto, observou-se que em Harris (2003) as mesmas linhas só são exibidas para o grupo de letras cujo procedimento é melhor detalhado, o que representa apenas $15 \%$ do alfabeto.

Uma referência existente em todos os casos foi a exibição de imagens de exemplo, ou seja, o modelo do caractere perfeitamente executado. Ainda sobre imagens, o uso de imagens de referência - sejam exemplos do caractere em um texto, sejam imagens com objetos cujo nome é iniciado por determinada letra - foi observado somente na escrita escolar (figura 11). 
Figura 11 - Imagem de referência em um ductus escolar.

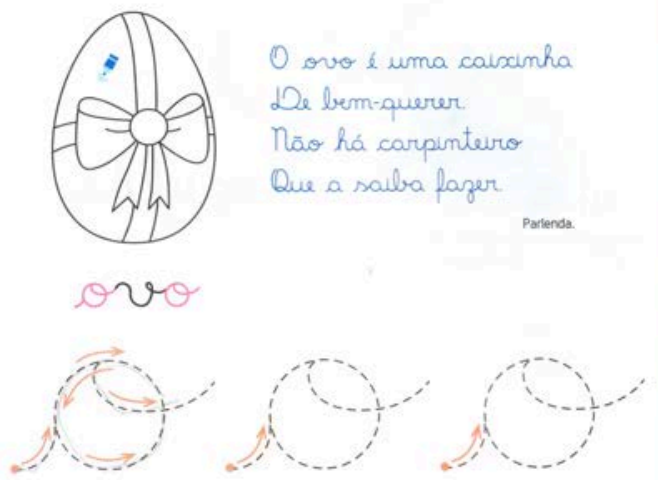

Fonte: Gabryelle e Carla (2013).

A exceção dos ductus retirados de Harris (2013), não foram observadas ferramentas de ênfase. Ductus como o da figura 12a foram exceções, prevalecendo SPPs como os da figura 12b. Os motivos que levam a esta configuração, não são objetos deste estudo, mas considerações sobre custo de impressão e de compreensão por parte do público alvo podem ser indícios para futuros estudos. Em Harris (2003), o principal recurso utilizado para enfatizar movimentos e traços foi o uso de cores e transparências. Nas capitulares imperiais dois novos recursos foram utilizados: o uso de quadros internos (para demonstrar alternativas de acabamento do ápice do caractere "A") e pequenos riscos nas hastes dos caracteres indicando o ângulo no qual a pena deve apresentar em cada ponto de execução. Enquanto o recurso do quadro interno foi utilizado somente para o ductus da letra "A" (figura 10), o recurso de demonstração do ângulo foi utilizado em todos as sequências do modelo.

Observou-se que em $100 \%$ dos procedimentos analisados o caractere era demonstrado tal como foi desenhado. Apenas nos casos dos SPPs discretos específicos para as letras "o", "n", "g", "s", "I", "S", "T" e "V" é que o caractere também é demonstrado de forma fotográfica.

Figura 12 - (a) Imagem de referencia e (b) um ductus histórico.

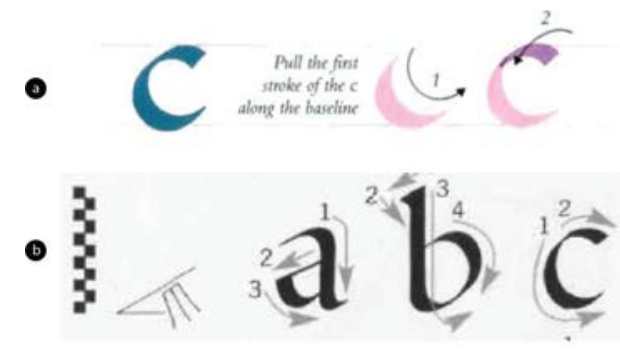

Fonte: Harris $(2003,2013)$.

Seja qual for o estilo de imagem, a representação dos caracteres total foi observada em quase todos os modelos explorados. O único caractere que não foi representado de forma completa foi o "H" das capitulares imperiais. Em sua sequência, o caractere é utilizado como referência também para as letras "I" e "J", por sua proximidade formal, e isso compromete a sua representação completa. As representações parciais foram observadas em SPPs discretas, aqueles que se utilizavam mais de um quadro para demonstrar o procedimento. $O$ outro caso onde 
observou-se a representação parcial da imagem foi observado na demonstração de ápices alternativos para o "A" capitular imperial. Ao invés de ser demonstrado a mesma letra três vezes, isolou-se a região que diferencia cada caractere, exibindo-a somente no detalhe da SPP.

\section{Considerações Finais}

A análise desenvolvida mostrou direcionamentos importantes para o ensino de caligrafia, seja ela histórica ou escolar. As variações se repetiam nos grupos de caracteres analisados durante o estudo, possivelmente pela variação de amostras que foram utilizadas. Por este motivo, este estudo de caráter exploratório buscou iniciar uma discussão a respeito de um dos principais elementos da caligrafia - o ductus - observando-o não só como uma estrutura ou caminho para o traço caligráfico, mas sim como um esquema pictórico de procedimentos que funciona como ferramenta auxiliar para o ensino e o aprendizado da caligrafia. Por se tratar de um estudo preliminar, a análise não foi aprofundada e serviu principalmente para avaliar as variações sugeridas e criar novos questionamentos para uma pesquisa futura: Será que o ductus caligráfico sendo ele observado como uma SPP - possui grandes variações? Quais fatores influenciam mais fortemente essas diferenças? É possível dizer se as instruções e procedimentos mostrados nos ductus são claros o suficiente para calígrafos iniciantes ou pessoas em processo de aprendizagem da escrita? Para que essas e outras questões possam ser respondidas, é necessário estender a aplicação do framework de análise a outros modelos de caligrafia e outros autores.

O ductus na caligrafia escolar tem uma apresentação muito mais simplificada, se repetindo também para todas as letras. Atribuímos isso ao fato do professor fazer o papel de um mediador da SPP para a criança em condição de aprendizado da escrita, sendo assim, informações extras e mais complexas podem ser passadas de acordo com as necessidades individuais dos alunos. Por outro lado, na caligrafia histórica, o ductus caligráfico precisa ter o máximo de informação possível - por isso o uso de rótulos, legendas e dos dispositivos simbólicos, como setas, cores e imagens de exemplo - já que na maioria dos casos a instrução é lida por um aprendiz adulto e sem auxílio de um professor.

O estudo gerou dois frameworks para análise do ductus caligráfico, sendo o primeiro mais descritivo e baseado em Spinillo (2000) e o segundo, que foi uma evolução do seu antecessor, em busca de uma forma menos descritiva de coletar dados, funcionando como uma checklist onde era marcado o que era ou não encontrado em cada letra dos modelos analisados.

Por fim, após justificar que cada ductus é também uma SPP e criarmos um framework de análise para esse tipo de procedimento, identificamos que algumas das informações presentes na demonstração do modelo caligráfico como um todo são omitidas. Embora as análises terem sido feitas letra por letra, as considerações feitas servem para o modelo caligráfico como um todo. Sendo assim, em estudos futuros, o framework proposto nesta pesquisa deverá ser ampliado e aplicado também nas avaliações das informações complementares do modelo analisado. A aplicação do framework de maneira ampliada pode possibilitar a detecção de inconstâncias e erros nas SPPs, tanto dentro do mesmo modelo quanto de modelos semelhantes de outros autores, além de possibilitar a geração de recomendações para novas cartilhas e livros de caligrafia. 


\section{Referências Bibliográficas}

BRANCO, A. Oficina Caligrafia para Designers. Fortaleza, 2012.

DICIONÁRIO Michaelis da Língua Portuguesa. São Paulo: Editora Melhoramentos. Disponível em: http://michaelis.uol.com.br/. Acesso em 3 de Abril de 2018.

ESTEVES, I. L. A trajetória dos conceitos caligrafia e escrita. Disponível em: <www.sbhe.org.br>. Acesso em: 9 jun. 2016.

FERREIRO, E.; TEBEROSKY, A. Psicogênese da Língua Escrita. Porto Alegre: Artes Médicas Sul, 1999.

FETTER, S. Modelos caligráficos na escola brasileira: uma história do Renascimento aos nossos dias. [s.I.] Universidade do Estado do Rio de Janeiro, 2012.

GABRYELLE, T; CARLA, V. Essa Mãozinha Vai Longe: Caligrafia 2. 4ạ Ed. São Paulo: Editora do Brasil, 2013.

GIL, C. La Grafia. Disponível em: <http://lagrafia.blogspot.com.br/>. Acesso em: 21 jun. 2017.

HARRIS, D. A arte da caligrafia - um guia prático, histórico e técnico. São Paulo: Ambientes e Costumes Editora, 2013.

HARRIS, D. The Calligrapher's Bible: 100 Complete Alphabets and how to Draw Them. Nova lorque: Barron's, 2003.

HEITLINGER, P. Tipos e Fontes - Manual de Typeface Design, caligráfico e tipográfico. Portugal: Tipografos.net, 2011

LIMA, F. P. L. DE. O processo de construção de fontes digitais de simulação caligráfica. Rio de Janeiro: Universidade do Estado do Rio de Janeiro, 2009.

LOAIZA, F.; VALENCIA, J.; ARIAS, R. Caligrafía Expresiva, Arte y Diseño. Colômbia: Publiprint, 2010. MEDIAVILLA, C. Caligrafía: del signo caligráfico a la pintura abstracta. Valência: Campgràfic, 2005. NEWHALL, A. Calligraphy \& Letter Design: Learn the basics of creating elegant letter forms and discover of variety of styles and samples. Londres: Walter Foster Publishing, 1989.

RICHARDS, C. Getting the picture: diagram design and the information revolution. Information Design Journal, v. 9, n. 2/3, p. 87-110, 2000.

SMOLKA, A. L. B. A Criança na Fase Inicial da Escrita: a alfabetização como processo discursivo. 13a ed. São Paulo: Cortez, 2012.

SPINILLO, C. G. An analytical approach to procedural pictorial sequences. [s.I.] The University of Reading, 2000.

SPINILLO, C. G. Instruções visuais: algumas considerações e diretrizes para o design de sequências pictóricas de procedimentos. Estudos em Design, v. 9, n. 3, p. 31-50, 2002.

TWYMAN, M. The graphic presentation of language. Information Design Journal, v. 3, n. 1, p. 222, 1 jan. 1982.

TWYMAN, M. Using Pictorial Language: A Discussion of the Dimensions of the Problem. In: Designing Usable Texts. New York: Academic Press Inc., p. 245-312, 1985. 